\title{
Multivariate Statistical Analysis of Three-Spatial-Dimension ToF-SIMS Raw Data
}

Sets

V. S. Smentkowski ${ }^{1 *}$, S.G. Ostrowski ${ }^{1}$, E. Braunstein ${ }^{2}$, M.R. Keenan ${ }^{3}$, J.A. (Tony)

Ohlhausen $^{3}$, and P.G. Kotula ${ }^{3}$

${ }^{1}$ General Electric, Global Research, Niskayuna, NY 112309

${ }^{2}$ Lockheed Martin Missiles and Fire Control, Orlando, Florida 32819

${ }^{3}$ Sandia National Laboratories, Albuquerque, NM 87185

*corresponding author: smentkow@research.ge.com, 518-387-5467

\section{Supplementary Material:}

Figure S-1. A video clip of the color overlay shown in Figure 7. This video clip allows the analyst to view the data set from many perspectives; which provides for a better understanding of the sample composition. The 5 components identified by AXSIA are: $\mathrm{SiO}_{2}$ film (blue), GaAs substrate (green), $\mathrm{SiO}_{2} / \mathrm{GaAs}$ interface (yellow), deposits (cyan), and surface contaminants (red). The 5 components are shown sequentially after the overlay. Note that component intensity thresholding was used to generate this movie clip. 